\title{
Preparation, in vitro release, and pharmacokinetics in rabbits of lyophilized injection of sorafenib solid lipid nanoparticles
}

This article was published in the following Dove Press journal:

International Journal of Nanomedicine

16 June 2012

Number of times this article has been viewed

\section{Hong Zhang \\ Fu-Ming Zhang \\ Shi-Jun Yan}

Department of Pharmacy, Renmin Hospital of Wuhan University, Wuhan, People's Republic of China
Correspondence: Hong Zhang Department of Pharmacy, Renmin Hospital of Wuhan University, Wuhan 430060, People's Republic of China

Tel +86 278804 I9II

Fax +86 278804 | 9 | ।

Email zhzx8888@I63.com
Abstract: Sorafenib solid lipid nanoparticles (S-SLN) were prepared by emulsion evaporation-solidification at low temperature. Morphology was examined by transmission electron microscope. Particle size and zeta potential were determined by laser granularity equipment. Encapsulation efficiency (EE) was detected by Sephadex gel chromatography and high-performance liquid chromatography (HPLC). The in vitro release profile of S-SLN was studied with dialysis technology. The lyophilized injection of S-SLN was prepared by freeze drying and analyzed by differential scanning calorimetry. The plasma concentration of sorafenib in blood was determined by HPLC. The solid lipid nanoparticles assumed a spherical shape with an even distribution of diameter and particle size $108.23 \pm 7.01 \mathrm{~nm}(\mathrm{n}=3)$. The polydispersity index, zeta potential, and EE were determined to be $0.25 \pm 0.02,-16.37 \pm 0.65 \mathrm{mV}$, and $93.49 \% \pm 1.87 \%$, respectively $(n=3)$. The in vitro release accorded with the Weibull distribution model. An equal volume of $15 \%(\mathrm{w} / \mathrm{v})$ mannitol performed better as the protective agent for a lyophilized injection of S-SLN with a new material phase formation. The pharmacokinetic processes of sorafenib solution and lyophilized injection of S-SLN in vivo were in accordance with the two-compartment and one-compartment models, respectively. S-SLN nanoparticles are thus considered a promising drug-delivery system.

Keywords: sorafenib, solid lipid nanoparticles, material phase analysis, HPLC, release profile, pharmacokinetics

\section{Introduction}

\section{Sorafenib}

(4-[4-[[4-chloro-3-(trifluoromethyl)phenyl]carbamoylamino]phenoxy]-N-methylpyridine-2-carboxamide) (BAY 43-9006; Bayer HealthCare Pharmaceuticals, Leverkusen, Germany and Onyx Pharmaceuticals Emeryville, CA) (Figure 1) is a novel diaryl urea compound and its molecular formula is $\mathrm{C}_{21} \mathrm{H}_{16} \mathrm{ClF}_{3} \mathrm{~N}_{4} \mathrm{O}_{3}$. A moleculartargeted drug, Sorafenib is an oral multitargeted multikinase inhibitor, which targets the receptors serine, threonine, and tyrosine kinases such as Raf kinase, vascular endothelial growth factor receptor 2 (VEGFR-2), VEGFR-3, platelet-derived growth factor receptor- $\beta$, c-KIT, and FLt- $3^{1}$ which are involved in tumor cell proliferation and tumor angiogenesis.

Sorafenib has been approved for therapy in advanced renal cell cancer and hepatocellular cancer and is currently being investigated as therapy in other solid tumor malignancies ${ }^{2}$ and acute myelogenous leukemia, ${ }^{3,4}$ with two metabolic pathways in man: phase I oxidation mediated by cytochrome P450 (CYP3A4) and phase II conjugation mediated by UGT1A9. ${ }^{5}$ 


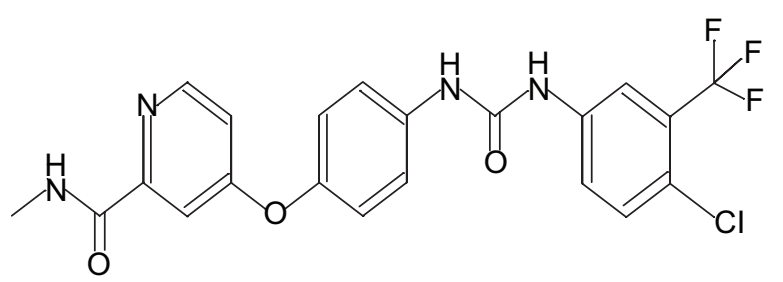

Figure I Chemical structure of sorafenib.

Sorafenib is currently clinically available in oral and tablet formulations. The low solubility of the oral solution results in low efficacy for patients. The two formulations are administrated orally and absorbed into the blood through the gastrointestinal tract, which causes low bioavailability due to the first-pass effect and a large adverse reaction in gastrointestinal irritation.

Solid lipid nanoparticles (SLN) are one of the new nanoparticle drug-delivery systems. SLNs are a solid colloidal drug-delivery system with sizes ranging from 50 to $1000 \mathrm{~nm}$, in which the drugs are wrapped into the lipid core with solid natural or synthetic lipids. As a new type of nanoparticle drug-delivery system, SLN has been used to control drug release after emulsions, liposomes, microparticles. ${ }^{6}$ It has many advantages, for example, good physiological compatibility, well-controlled drug release, good targeting, ${ }^{7,8}$ high physical stability similar to polymer nanoparticles, low toxicity, and large-scale production like liposomes and emulsions. The many administration routes for SLN include intravenous administration to achieve a targeted effect or controlledrelease, oral administration to control the drug release in the gastrointestinal tract, and local administration.

In this study, SLN were prepared using emulsion evaporation-solidification at low temperature, and SLN lyophilized powder was produced with a refrigerated air dryer. Some preliminary studies on the quality of the SLN structure, its physical and chemical properties, and effect of in vitro release were done. High-performance liquid chromatography (HPLC) was used to determine the action of sorafenib in rabbit plasma. The pharmacokinetics in rabbit of sorafenib solid lipid nanoparticles (S-SLN) was investigated to provide a reference for clinical application.

\section{Materials and methods \\ Materials}

The active pharmaceutical ingredient (API) for sorafenib was purchased from Chuangcheng Pharmaceutical Co, Ltd (Wuhan, China). Sorafenib control was purchased from Bayer HealthCare. Poloxamer 188 was purchased from Excellent Pratt and Whitney (Shenzhen, China), egg-phosphatidylcholine from National Medicines Co, Ltd (Shanghai, China), glyceryl behenate from Harmony Fine Chemical Co, Ltd (Wuhan, China) and Sephadex G-50 from Pharmacia (Shanghai, China). Ammonium acetate (analytical grade) and acetonitrile (HPLC grade) were both purchased from Bodi Chemical Co, Ltd (Tianjin, China). Deionized purified water was prepared in the laboratory and other reagents were all analytical grade. New Zealand rabbits (SPF level, female, $2.0 \pm 0.5 \mathrm{~kg}$ ) were purchased from the experimental animal center of Wuhan University (license number, SCXK(Hubei) 2008-0004).

\section{Methods}

\section{Preparation of S-SLN}

Sorafenib, glyceryl behenate, and egg-phosphatidylcholine were weighed accurately and dissolved in anhydrous ethanol $(10 \mathrm{~mL})$, forming an organic phase at $80^{\circ} \mathrm{C} \pm 2^{\circ} \mathrm{C}$ water bath. The aqueous phase consisted of poloxamer 188 and water $(30 \mathrm{~mL})$ at $80^{\circ} \mathrm{C} \pm 2^{\circ} \mathrm{C}$ water bath. The organic phase was slowly added to the water phase under mechanical stirring $(1000 \mathrm{rpm})$ at $80^{\circ} \mathrm{C} \pm 2^{\circ} \mathrm{C}$. After 2 hours, the volume was condensed by approximately half to obtain a semitransparent solution. The solution was quickly dispersed in the water (60 mL, temperatures ranging from 0 to $2^{\circ} \mathrm{C}$ ) by stirring for another 2 hours. A solid lipid nanoparticle suspension was obtained. The technological process of preparing S-SLN is shown in Figure 2.

The volume ratio of the organic phase/water phase, emulsifying temperature, proportion of original volume, volume ratio of nanoemulsion/ice-water bath, and stirring velocity were investigated to optimize the S-SLN preparation procedure for maximum encapsulation efficiency (EE) and proper particle size.

The proportion of various emulsifiers, carrier material, and sorafenib used had a great effect on the EE of SLN. Therefore, based on the pretests and single factor investigation, sorafenib, glyceryl behenate, egg-phosphatidylcholine, and poloxamer 188 were selected as four factors with each factor having three levels. The experiment was performed according to the principle of orthogonal design.

A $2 \mathrm{~mL}$ suspension of S-SLN was sampled onto a Sephadex G-50 gel column $(160 \mathrm{~mm} \times 10 \mathrm{~mm})$ with distilled water as the eluent. The light blue opalescent eluent of between 6.0 and $14.0 \mathrm{~mL}$ was collected and demulsified with $2.0 \mathrm{~mL}$ acetonitrile. The separation solution was denoted as A. Another $2.0 \mathrm{~mL}$ of S-SLN suspension was directly added to $2.0 \mathrm{~mL}$ acetonitrile for de-emulsification. Then, it was diluted to the same volume as A with distilled 


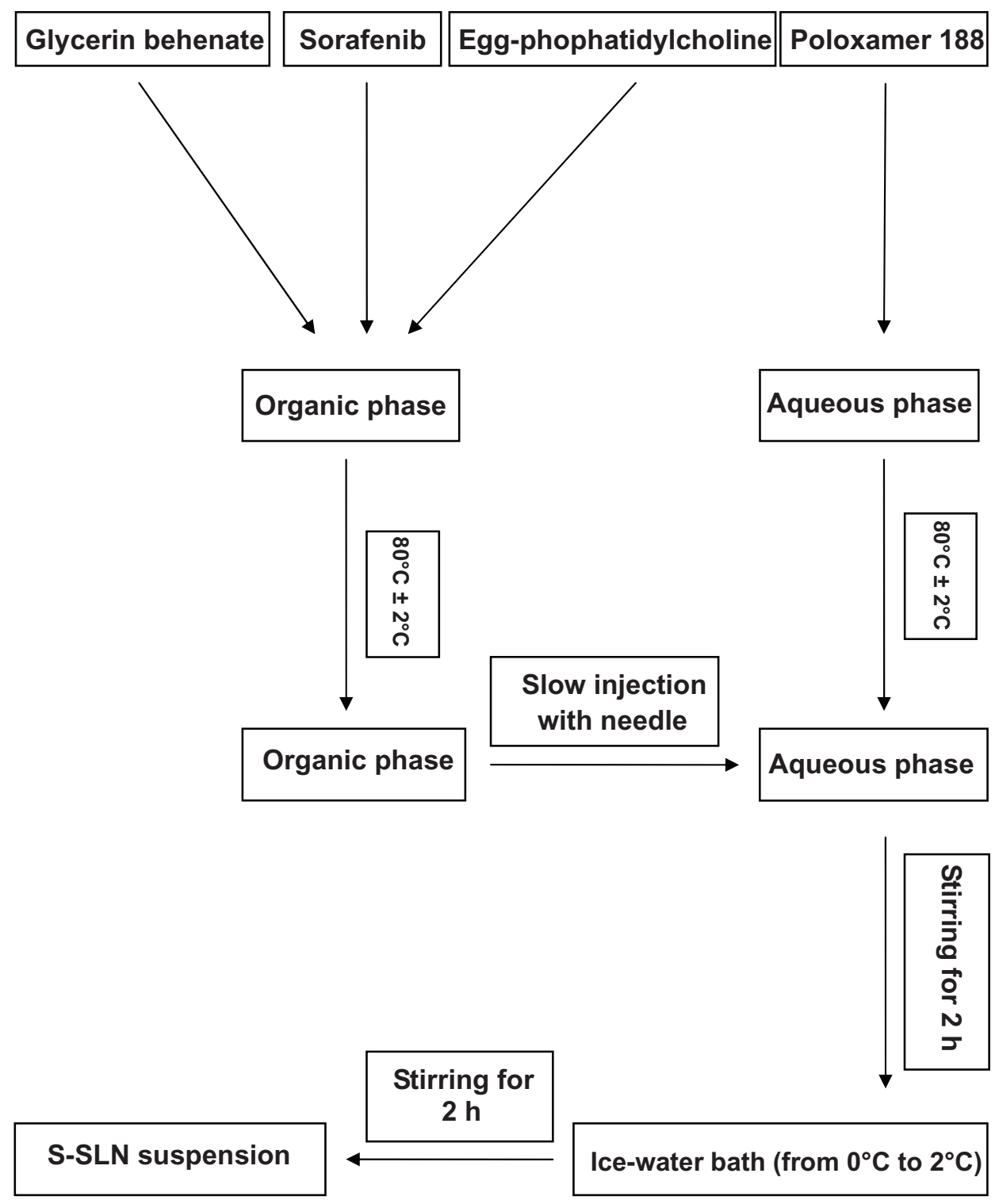

Figure 2 Schematic representation of technological process of preparation of S-SLN. Abbreviation: S-SLN, sorafenib solid lipid nanoparticle singular.

water, and this solution was denoted as $\mathrm{B}$. The EE was assessed using the following equation (1):

$$
\mathrm{EE} \%=\left(\frac{\text { Sorafenibin } \mathrm{A}}{\text { Sorafenibin } \mathrm{B}}\right) \times 100
$$

\section{Physiochemical characteristics of S-SLN}

The particle size and zeta potential were determined using a Zetasizer 3000 laser particle size analyzer (Malvern Instruments, Malvern, UK). The morphology of S-SLN was observed under a transmission electron microscopy (TEM; JEOL Ltd., Akishima, Japan).

In vitro sorafenib release from S-SLN was studied in simulated blood (phosphate-buffered saline [PBS], $\mathrm{pH}$ 7.4).
A prepared dialysis bag containing $2 \mathrm{~mL}$ suspensions of S-SLN was incubated in the PBS release medium $(150 \mathrm{~mL})$ at $37^{\circ} \mathrm{C} \pm 1^{\circ} \mathrm{C}$ under mild stirring $(120 \mathrm{rpm})$. At predetermined time intervals $(0.5,1.0,1.5,2.0,3.0,4.0,5.0,6.0,7.0,9.0$, 11.0 , and 12.5 hours), an aliquot of $1 \mathrm{~mL}$ was taken from the supernatant (PBS). After removal of the supernatant, the same volume of fresh PBS was replaced. The amount of the sorafenib within the collected supernatant was measured by HPLC.

\section{Preparation of S-SLN lyophilized powder}

Three substances were chosen as the cryoprotectant: $15 \%(\mathrm{w} / \mathrm{v})$ trehalose, $15 \%(\mathrm{w} / \mathrm{v})$ mannitol, and $5 \%$ $(\mathrm{w} / \mathrm{v})$ trehalose $+5 \%(\mathrm{w} / \mathrm{v})$ mannitol. Two microliters of cryoprotectant and $2.0 \mathrm{~mL}$ suspensions of S-SLN at a ratio 
of $(1: 1, \mathrm{v} / \mathrm{v})$ was added to the vial $(7 \mathrm{~mL})$. The vial was prefrozen for 12 hours at $-74^{\circ} \mathrm{C}$ and, after the solution was added, kept in the refrigerated air dryer for another 24 hours to obtain the S-SLN lyophilized powder.

The sorafenib API, blank accessories, physical mixtures (sorafenib, glyceryl behenate, egg-phosphatidylcholine and poloxamer 188), and S-SLN lyophilized powder were analyzed by differential scanning calorimetry (DSC). Briefly, each $\sim 10 \mathrm{mg}$ sample was placed onto standard aluminum pans and sealed. An empty pan was used as a reference. DSC was performed at a heating rate of $10^{\circ} \mathrm{C} / \mathrm{min}$ under a nitrogen atmosphere. Aluminum oxide was used as a standard material to calibrate the temperature and energy scales of the DSC instrument.

\section{Pharmacokinetic behavior in vivo}

To evaluate the pharmacokinetic behavior of S-SLN in vivo, an animal experiment was performed using New Zealand rabbits weighing $2.0 \pm 0.5 \mathrm{~kg}$. Eight rabbits were divided equally into control and experimental groups with an intravenous injection of $20 \mathrm{mg} / \mathrm{kg}$ sorafenib solution and $20 \mathrm{mg} / \mathrm{kg}$ lyophilized S-SLN in an auricular vein, respectively. The rabbits were fasted for 12 hours before administration. Blood samples from an ear were collected at predetermined time intervals after injection. The blood samples were centrifuged at 10,000 rpm for 2 min and the supernatant was kept at $-20^{\circ} \mathrm{C}$.

All results were expressed as mean \pm standard deviation or median, mean, and range, depending on data types. Analysis of variance was performed using SPSS software (v. 13.0 for Windows; SPSS Inc, Chicago, IL).

\section{Results}

\section{Preparation of S-SLN}

A single factor experiment was performed for the exploration of the preparation. The results were as follows: the volume ratio of organic phase/water phase was 1:3, emulsification temperature was $80^{\circ} \mathrm{C} \pm 2^{\circ} \mathrm{C}$, stirring velocity was $1000 \mathrm{rpm}$, volume ratio of the nanoemulsion/ice-water bath was $1: 3$, and a proportion of concentrated original volume is $1: 2$.

On this basis, an orthogonal design was performed to further optimize the S-SLN. The amount of sorafenib (A), glyceryl behenate (B), egg-phosphatidylcholine (C), and poloxamer 188 (D) were chosen as four factors. Three levels were considered for each factor (Table 1) and the results of the orthogonal test (Table 2) and variance analysis (Table 3) find that the $\mathrm{R}$ value is in the order: $\mathrm{A}>\mathrm{C}>\mathrm{B}>\mathrm{D}$, which indicates that the amount of sorafenib is the most significant
Table I Factors and levels of the orthogonal test

\begin{tabular}{lllll}
\hline & A (mg) & B (mg) & C (mg) & D (mg) \\
\hline 1 & 6 & 110 & 150 & 160 \\
2 & 8 & 160 & 250 & 210 \\
3 & 10 & 210 & 350 & 260 \\
\hline
\end{tabular}

influence among the four factors. The analysis results of every factorwere in the order: $\mathrm{A}_{1}>\mathrm{A}_{2}>\mathrm{A}_{3}, \mathrm{~B}_{2}>\mathrm{B}_{1}>\mathrm{B}_{3}, \mathrm{C}_{3}>\mathrm{C}_{2}>\mathrm{C}_{1}$, and $\mathrm{D}_{2}>\mathrm{D}_{3}>\mathrm{D}_{1}$. The results of an analysis of variance show that the A factor has significant influence $(P<0.05)$, and the $\mathrm{B}, \mathrm{C}$, and $\mathrm{D}$ factors have no significant influence $(P>0.05)$. Therefore, the best formula combination is $\mathrm{A}_{1} \mathrm{~B}_{2} \mathrm{C}_{3} \mathrm{D}_{2}$ in which the amounts of sorafenib, glyceryl behenate, egg-phosphatidylcholine, and poloxamer 188 are $6 \mathrm{mg}, 160 \mathrm{mg}, 350 \mathrm{mg}$, and $210 \mathrm{mg}$, respectively. The three batches of S-SLN were prepared in accordance with the optimized formula process, to obtain SLN with a particle size of $108.23 \pm 7.01 \mathrm{~nm}$, zeta potential of $-16.37 \pm 0.65 \mathrm{mV}$, a polydispersity index (PDI) of $0.25 \pm 0.02$, and an EE of $93.49 \% \pm 1.87 \%(\mathrm{n}=3)$.

\section{SLN characterization}

TEM was used to visualize the S-SLN in more detail. Figure 3 shows its surface morphology, which is a spherical particle. Figures 4 and 5 show the average particle sizes and zeta potential value of the prepared SLN, respectively. The particle size, PDI, and zeta potential are $108.23 \pm 7.01 \mathrm{~nm}$, $0.25 \pm 0.02$, and $-16.37 \pm 0.65 \mathrm{mV}$, respectively.

Figure 6 shows the release profile of sorafenib from S-SLN in vitro. The S-SLN cumulative release curve was fitted using the release model. Table 4 shows the fitting equation. The

Table 2 The scheme and results of $L_{9}\left(3^{4}\right)$ orthogonal test

\begin{tabular}{llllll}
\hline No & A & B & C & D & EE\% \\
\hline $\mathrm{I}$ & $\mathrm{I}$ & $\mathrm{I}$ & $\mathrm{I}$ & $\mathrm{I}$ & 78.35 \\
2 & $\mathrm{I}$ & 2 & 2 & 2 & 94.74 \\
3 & $\mathrm{I}$ & 3 & 3 & 3 & 84.41 \\
4 & 2 & $\mathrm{I}$ & 2 & 3 & 67.48 \\
5 & 2 & 2 & 3 & $\mathrm{I}$ & 74.02 \\
6 & 2 & 3 & $\mathrm{I}$ & 2 & 57.20 \\
7 & 3 & $\mathrm{I}$ & 3 & 2 & 73.42 \\
8 & 3 & 2 & $\mathrm{I}$ & 3 & 63.87 \\
9 & 3 & 3 & 2 & $\mathrm{I}$ & $59.3 \mathrm{I}$ \\
$\mathrm{K}_{1}$ & 257.50 & 219.25 & 199.42 & 211.68 & \\
$\mathrm{~K}_{2}$ & 198.70 & 232.63 & 221.53 & 225.36 & \\
$\mathrm{~K}_{3}$ & 196.60 & 200.92 & 231.85 & 215.76 & \\
$\bar{K}_{1}$ & 85.83 & 73.08 & 66.47 & 70.56 & \\
$\bar{K}_{2}$ & 66.23 & 77.54 & 73.84 & 75.12 & \\
$\bar{K}_{3}$ & 65.53 & 66.97 & 77.28 & 71.92 & \\
$\mathrm{R}$ & 20.30 & 10.57 & $10.8 \mathrm{I}$ & 4.56 & \\
\hline
\end{tabular}

Note: Encapsulation efficiency $(E E)$ was expressed as mean $(n=3)$. 
Table 3 The results of variance analysis

\begin{tabular}{llllll}
\hline Sources of variance & SS & df & MS & F & P \\
\hline A & 796.74 & 2 & 398.37 & 24.23 & $<0.05$ \\
B & 168.95 & 2 & 84.47 & 5.14 & $>0.05$ \\
C & 183.01 & 2 & 91.50 & 5.57 & $>0.05$ \\
D & 32.88 & 2 & 16.44 & 1.00 & $>0.05$ \\
Error & 32.88 & 2 & 16.44 & & \\
\hline
\end{tabular}

Note: $F_{0.05}(2,2)=19.00$.

Abbreviations: DF, degrees of freedom; F, F ratio; SS, sum of square of deviations; MS, mean square.

Weibull equation better described the process $(r=0.9763)$, therefore the equation of $\ln \ln [1 /(1-\mathrm{Q})]=0.6308 \ln \mathrm{t}-3.1033$ can be used to describe the release profile for S-SLN.

\section{Preparation of lyophilized powder}

The appearance, dissolution time, solution color, and mean particle size of the lyophilized powder of S-SLN, with different type, concentration (w/v), and cryoprotectant composition are
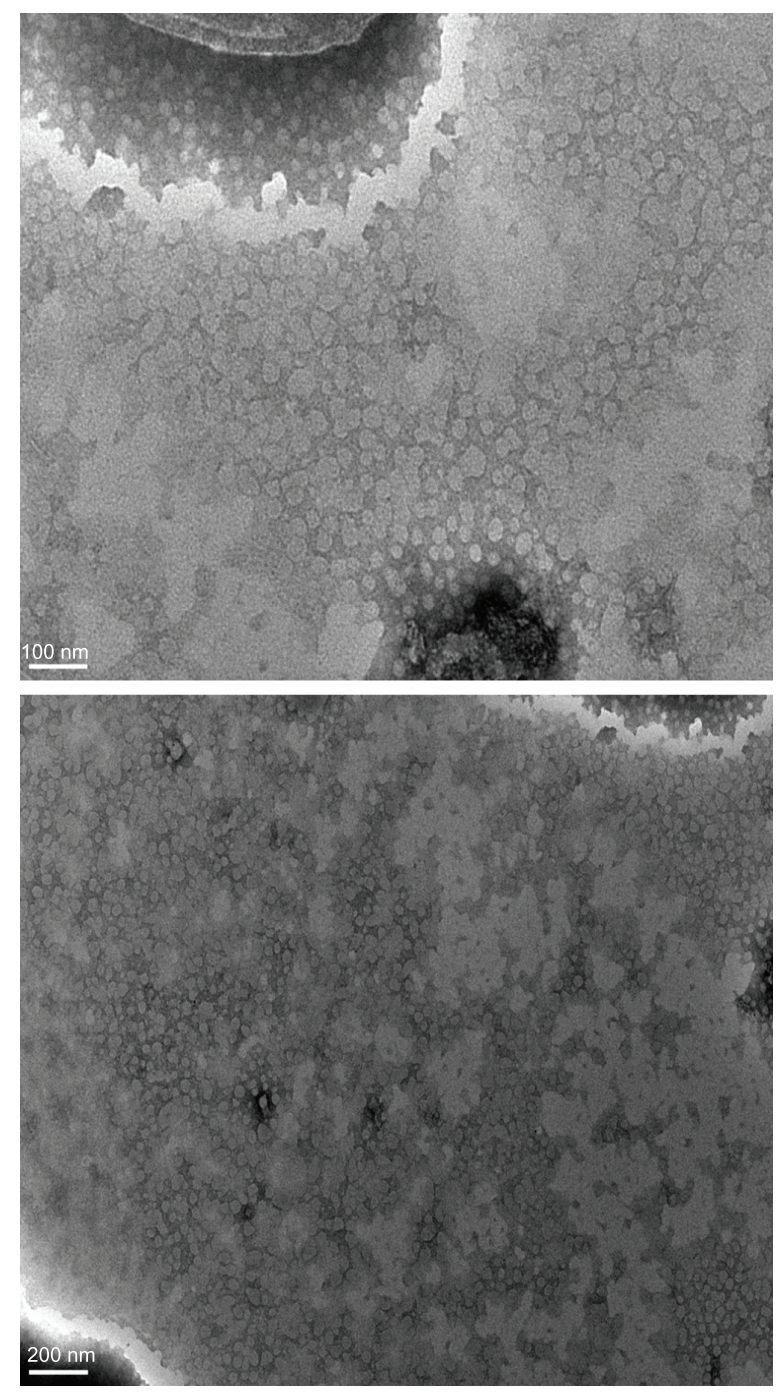

Figure 3 TEM photograph of S-SLN.

Abbreviation: S-SLN, sorefenib solid lipid nanopraticles.

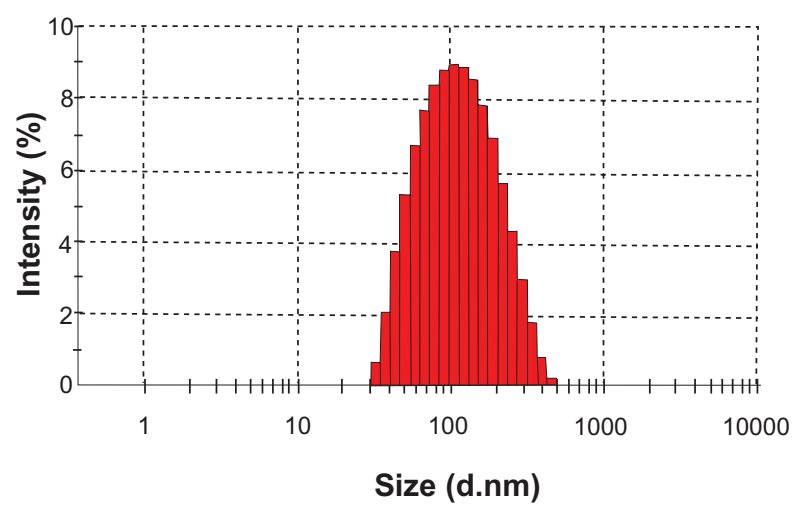

Figure 4 Size distribution of S-SLN.

Abbreviation: S-SLN, sorefenib solid lipid nanopraticles.

shown in Table 5 . When the cryoprotectant is $15 \%$ mannitol $(\mathrm{w} / \mathrm{v})$, the prepared S-SLN has the smallest changes in particle size, shorter dissolution time, and a stable solution system.

Sorafenib API has a single endothermic peak at around $210.24^{\circ} \mathrm{C}$, the peak temperatures of poloxamer 188 varies from $52.95^{\circ} \mathrm{C}$ to $56.49^{\circ} \mathrm{C}$, glyceryl behenate from $59.05^{\circ} \mathrm{C}$ to $70.33^{\circ} \mathrm{C}$, egg-phosphatidylcholine from $49.48^{\circ} \mathrm{C}$ to $51.46^{\circ} \mathrm{C}$, and physical mixtures (sorafenib, glyceryl behenate, eggphosphatidylcholine and poloxamer 188) from $49.25^{\circ} \mathrm{C}$ to $73.92^{\circ} \mathrm{C}$ (Figure 7). However, two endothermic peaks were found from $44.48^{\circ} \mathrm{C}$ to $49.57^{\circ} \mathrm{C}$ and $181.66^{\circ} \mathrm{C}$ to $185.66^{\circ} \mathrm{C}$ in the thermogram of the S-SLN lyophilized powder. The appearance of new peaks indicates the formation of a new material phase, which proved the formation of SLNs.

\section{Pharmacokinetics in vivo}

The chromatography system (Agilent 1100; Agilent Technologies, Palo Alto, CA) consisted of a quaternary gradient pump, a UV detector, G137PA automatic degasser, a standard autosampler, a column oven, and a chromatography workstation (Agilent Technologies).

Following Blanchet et $\mathrm{al}^{9}$ and Afify et $\mathrm{al}^{10}$ and preliminary experiments, all sorafenib samples were analyzed

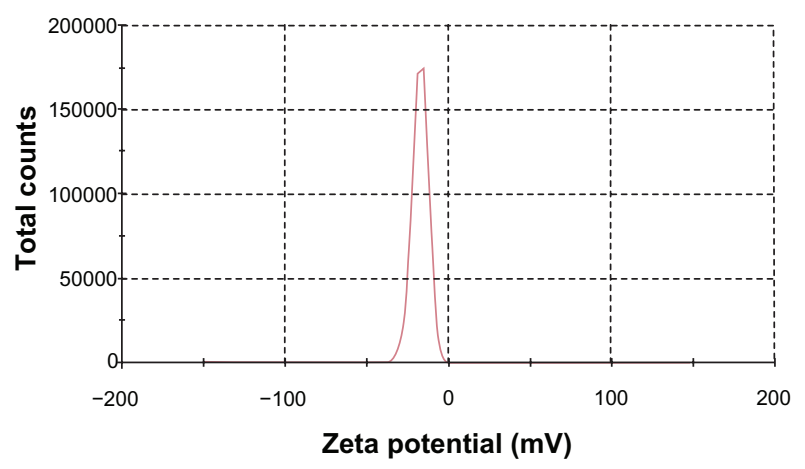

Figure 5 Zeta potential distribution of S-SLN.

Abbreviation: S-SLN, sorefenib solid lipid nanopraticles. 


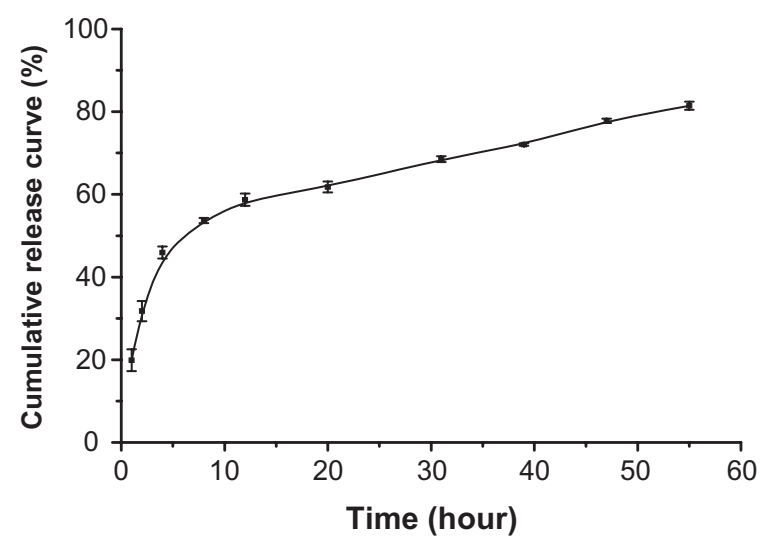

Figure 6 In vitro release of sorafenib from SLN in $\mathrm{pH} 7.4$ phosphate-buffer solution at $37^{\circ} \mathrm{C} \pm 1{ }^{\circ} \mathrm{C}$.

Note: Data represent mean \pm SD $(n=3)$.

Abbreviation: SLN, solid lipid nanopraticles.

following this HPLC method: an Inertsil ODS-3 column $(250 \mathrm{~mm} \times 4.6 \mathrm{~mm}$ length $\times$ internal diameter, $5 \mu \mathrm{m}$ particle size) (Agilent Technologies), a mobile phase consisting of acetonitrile: ammonium acetate buffer $50 \mathrm{mM}(72: 28, \mathrm{v} / \mathrm{v})$ filtered under vacuum through a $0.45 \mu \mathrm{m}$ nylon membrane filter, a flow rate set at $1.0 \mathrm{~mL} / \mathrm{min}$, a detection wavelength at $265 \mathrm{~nm}$, a temperature of column at $40^{\circ} \mathrm{C}$ and an injection volume of $20 \mu \mathrm{L}$.

First, $200 \mu \mathrm{L}$ of plasma sample was added to $2 \mathrm{~mL}$ of Eppendorf tube and $200 \mu \mathrm{L}$ acetonitrile was added to the precipitate protein. The tubes were vortexed for $1 \mathrm{~min}$, and centrifuged at 10,000 rpm for $10 \mathrm{~min}$. The obtained supernatant was transferred into a glass tube containing $1 \mathrm{~mL}$ of deionized, purified water. Then $3 \mathrm{~mL}$ of ethyl acetate was added to extract sorafenib. After agitation for $5 \mathrm{~min}$ with a mechanical shaker, the tubes were centrifuged at $4000 \mathrm{rpm}$ for $10 \mathrm{~min}$. The obtained supernatant was transferred into a $5 \mathrm{~mL}$ glass tube and evaporated to dryness in a $25^{\circ} \mathrm{C}$ water bath under a nitrogen stream. The residue was dissolved in $300 \mu \mathrm{L}$ of methanol. Twenty microliters of each sample was injected into the chromatographic system.

The method we developed was validated with respect to its specificity, linearity, precision, recovery, and sensitivity. The blank plasma, blank plasma + sorafenib control solution, and

Table 4 Fitting equation of the accumulative release percentage of sorafenib SLN in vitro

\begin{tabular}{lll}
\hline Models & Equations & $\mathbf{r}$ \\
\hline Zero-order kinetics & $\mathrm{Q}=0.0147 \mathrm{t}+0.027 \mathrm{I}$ & $0.927 \mathrm{I}$ \\
One-order kinetics & $\ln (\mathrm{I}-\mathrm{Q})=-0.0164 \mathrm{t}-0.0263$ & 0.9379 \\
Higuchi equation & $\mathrm{Q}=0.067 \mid \mathrm{t}_{1 / 2}-0.0375$ & 0.9744 \\
Weibull equation & $\ln \ln [\mathrm{I} /(\mathrm{I}-\mathrm{Q})]=0.6308 \ln \mathrm{t}-3.1033$ & 0.9763 \\
Ritger-Peppas equation & $\ln \mathrm{Q}=0.5958 \ln \mathrm{t}-3.1 \mathrm{I} 34$ & 0.9739 \\
\hline
\end{tabular}

Abbreviation: SLN, solid lipid nanopraticles. plasma samples collected after S-SLN administration were manipulated based on the HPLC method described above. The chromatogram was recorded (Figure 8). We found that the endogenous substances in plasma do not interfere with the determination of sorafenib in the plasma under the selected chromatographic conditions. Therefore, the specificity of the method is satisfying. Different concentrations of standard solution in plasma were prepared for the curve. The solutions were manipulated based on the HPLC method described above. The linear equation was $\mathrm{A}=101.6126 \mathrm{C}-16.2033$ $(\mathrm{r}=0.9992)$ in the concentration ranging from 0.2 to $20.0 \mu \mathrm{g} / \mathrm{mL}$, in which $\mathrm{A}$ is the peak area of sorafenib and $\mathrm{C}$ the concentration $(\mu \mathrm{g} / \mathrm{mL})$. As the intra- and interday precisions are within the acceptance criteria of $5 \%$, the method is precise (Table 6) and meets the requirements for biological sample analysis. The high, medium, and low concentrations of the sorafenib control solution were prepared and added to the blank plasma, which was manipulated based on the plasma samples processing method. The percentage recoveries were calculated, and the results are represented in Table 7. The results show that the method recovery meets the requirement of biological sample analysis. The limit of detection (LOD) and lower limit of quantification (LLOQ) were determined to check the sensitivity of the method. The LOD and LLOQ values were $0.1 \mu \mathrm{g} / \mathrm{mL}$ and $0.2 \mu \mathrm{g} / \mathrm{mL}$, respectively.

According to the maximum tolerated dose and safety dose in humans and pretests, the amount of sorafenib for safe intravenous injection was determined as $20 \mathrm{mg} / \mathrm{kg}$. The rabbits kept normal life in 2 weeks.

The collected plasma samples were handled according to the plasma samples processing method. The sorafenib concentrations in plasma at different times were determined by HPLC, the results were calculated, and the obtained mean concentration-time curve is shown in Figure 9. The obtained data of the mean concentration of sorafenib and S-SLN in plasma at different times were fitted using the 3P97 Practical Pharmacokinetic Program worked out by the Chinese Pharmacological Society and Mathematics Professional Committee. The compartment model was determined by Akaike's information criterion (AIC) and relevant equation coefficients. Pharmacokinetic parameters are shown in Tables 8 and 9 . These results show that the sorafenib solution was most efficient in the two-compartment model in rabbits, the weight coefficient of which was $1 / \mathrm{C}^{2}$. However, the S-SLN was most efficient in the one-compartment model, the weight coefficient of which was $1 / \mathrm{C}^{2}$.

S-SLN was eliminated slowly, with an elimination rate only 0.14 times slower than the sorafenib solution, which showed that SLN had an obvious sustained release effect, 
Table 5 The appearance, dissolution time, solution color and mean particle size of the lyophilization powder of S-SLN

\begin{tabular}{|c|c|c|c|c|}
\hline $\begin{array}{l}\text { Numbers (lyophilize } \\
\text { powder) }\end{array}$ & Appearance & $\begin{array}{l}\text { Dissolution time } \\
\text { (minute) }\end{array}$ & Solution color & Particle size (nm) \\
\hline S-SLN & $\begin{array}{l}\text { Milky, leavening and porous, edge } \\
\text { of scattering-like }\end{array}$ & 2.0 & Milky, translucent, clarified & $\begin{array}{l}\text { Two peaks: }|||| .4 \mid \pm 3.20 \\
\text { and } 53|.03 \pm 4.7|\end{array}$ \\
\hline Mannitol & $\begin{array}{l}\text { White like snow, dense } \\
\text { surface, like pie }\end{array}$ & 5.0 & $\begin{array}{l}\text { Translucent, clarified, microsmall } \\
\text { amount of precipitate }\end{array}$ & $|4| .34 \pm 2.7 \mid$ \\
\hline Trehalose & $\begin{array}{l}\text { Similar to the color of trehalose, } \\
\text { leavening and porous surface, } \\
\text { closely packed like foam }\end{array}$ & 2.5 & $\begin{array}{l}\text { Translucent, clarified, small } \\
\text { amount of particles }\end{array}$ & $222.53 \pm 6.44$ \\
\hline $\begin{array}{l}\text { Mannitol + trehalose } \\
(I: I, v / v)\end{array}$ & $\begin{array}{l}\text { Milky, leavening and porous, } \\
\text { edge of grid }\end{array}$ & 3.0 & $\begin{array}{l}\text { Clarified, small amount of } \\
\text { precipitate }\end{array}$ & $331.02 \pm 3.61$ \\
\hline
\end{tabular}

Abbreviation: SLN, solid lipid nanopraticles.

putting off the drug release rate and prolonging the drug retention time in blood (Table 9). In addition, the area under the receiver operating characteristic curve of the S-SLN is 7.08 times greater than the sorafenib solution, which showed that the bioavailability of sorafenib was greatly improved when was it added to a SLN.

\section{Discussion}

Particle size is an important factor in evaluating drugloaded nanoparticles in vivo. Generally speaking, a small nanoparticle has a small curvature radius and weak adsorption action with protein within the systemic circulation. Therefore, reducing the particle size could prolong retention

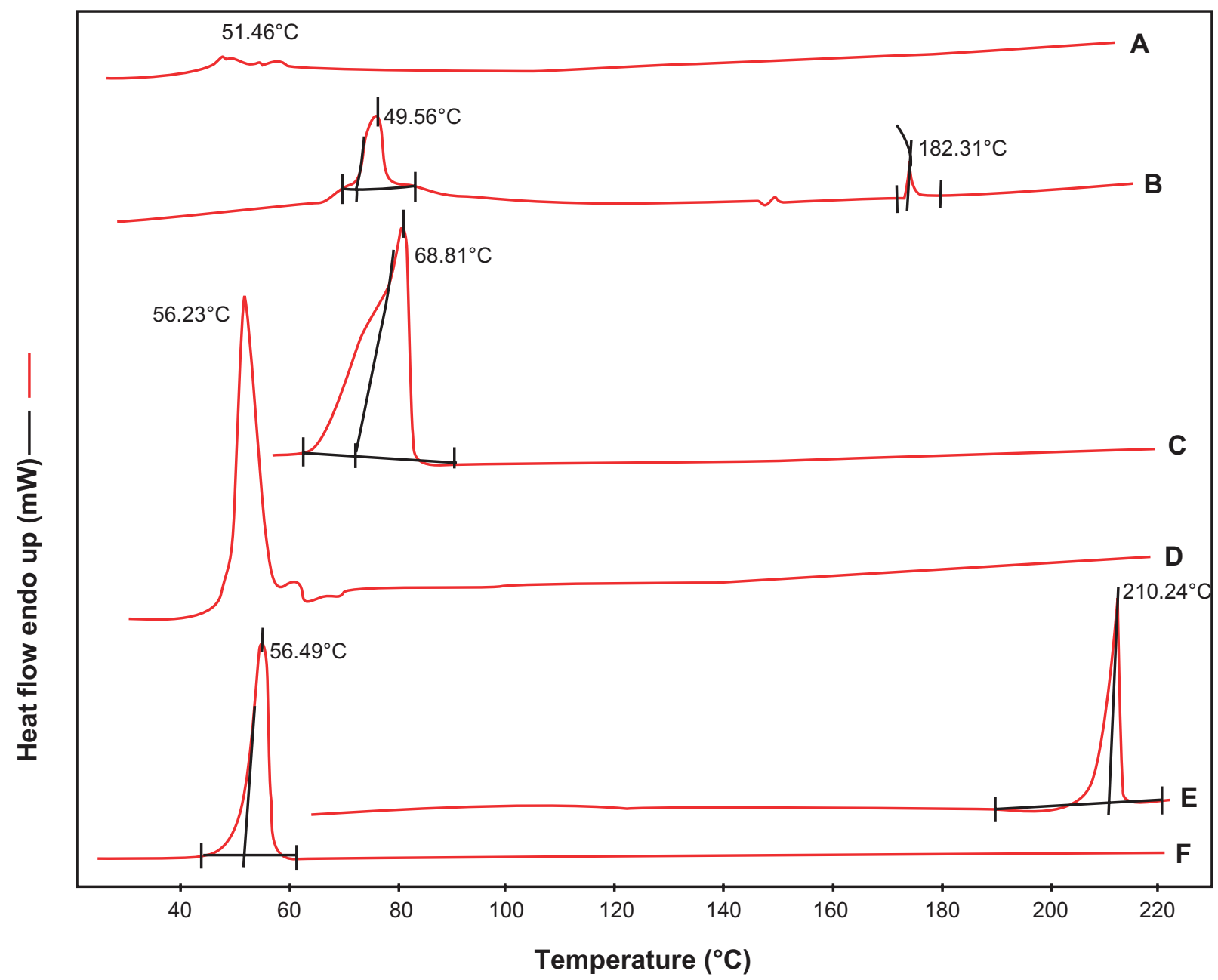

Figure 7 DSC thermograms of (A) egg-phophatidylcholine, (B) S-SLN, (C) glycerin behenate, (D) physical mixture of poloxamer I88, sorafenib, glycerin behenate, EPC, (E) sorafenib and $(\mathbf{F})$ poloxamer 188.

Abbreviations: DSC, differential scanning calorimetry; EPC, egg-phosphatidylcholine; S-SLN, sorafenib solid lipid nanoparticle. 


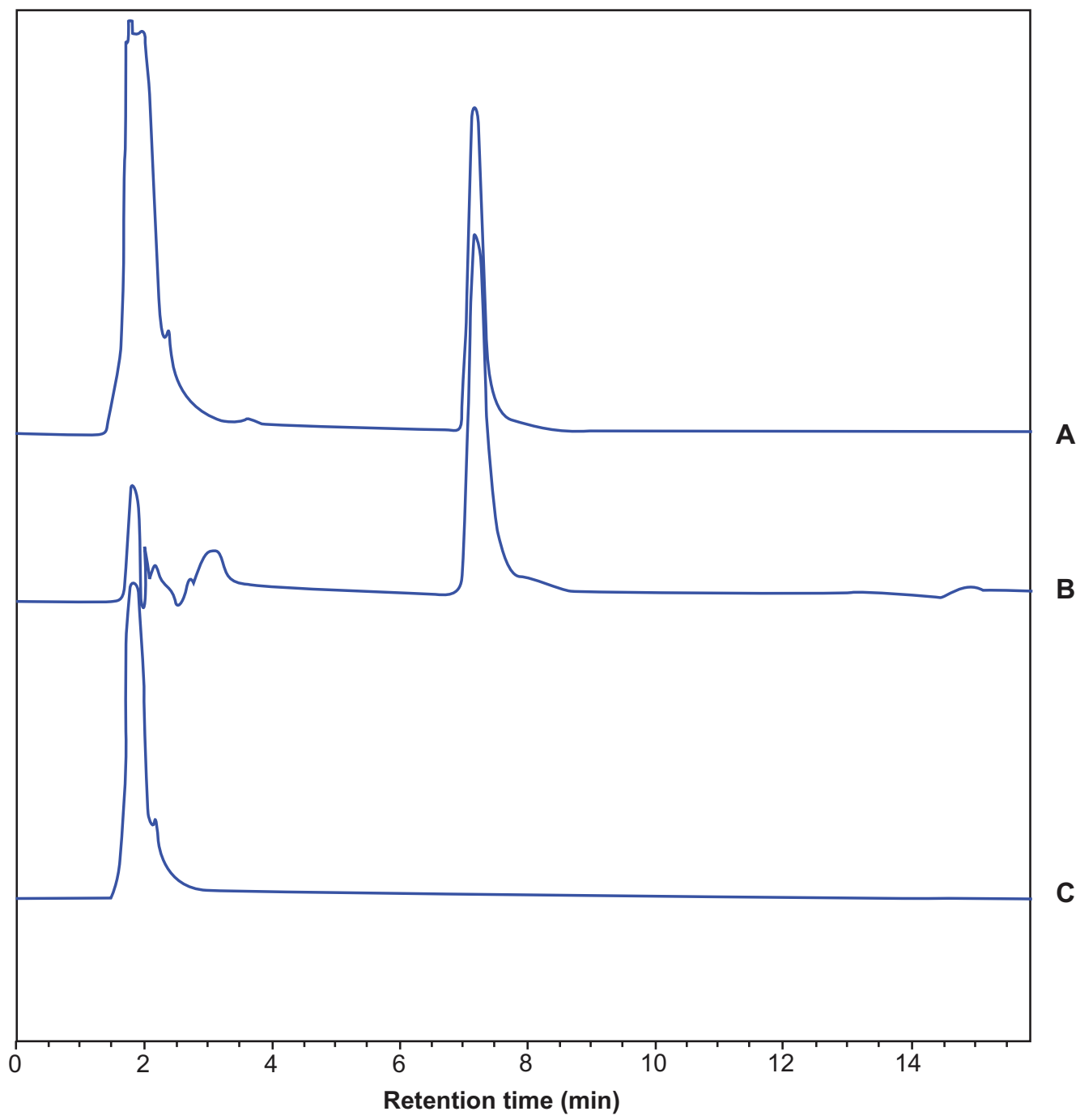

Figure 8 HPLC chromatogram of (A) sorafenib control in blank plasma, (B) plasma sample after S-SLN administration and (C) blank plasma. Abbreviations: HPLC, high-performance liquid chrematography; S-SLN, sorafenib solid lipid nanopraticle.

time and avoid being trapped by the sinusoidal tubules in the liver and spleen. ${ }^{11}$ However, when the particle size is less than $70 \mathrm{~nm}$, the aggregation occurred in the liver is obvious, which is detrimental to retention within the systemic circulation. Therefore a particle size ranging from 70 to $200 \mathrm{~nm}$ is a good choice and this nanoparticle size also affects its toxicity in vivo and excretion. ${ }^{12}$ Particle size is a key point for preparation of S-SLNs. In this experiment, we

Table 6 The results of accuracies

\begin{tabular}{|c|c|c|}
\hline \multirow{2}{*}{$\begin{array}{l}\text { Theoretic } \\
\text { Concentration } \\
(\mu \mathrm{g} / \mathrm{mL})\end{array}$} & \multicolumn{2}{|l|}{ Intraday } \\
\hline & \multicolumn{2}{|c|}{$\begin{array}{l}\text { Detectable concentration } \\
(\mu \mathrm{g} / \mathrm{mL})\end{array}$} \\
\hline 20.0 & $20.04 \pm 0.30$ & $20.38 \pm 0.94$ \\
\hline 2.0 & $1.96 \pm 0.02$ & $1.98 \pm 0.07$ \\
\hline 0.2 & $0.21 \pm 0.01$ & $0.24 \pm 0.01$ \\
\hline
\end{tabular}

Note: Mean \pm standard deviation, $n=5$. used the glyceryl behenate as carrier material and the eggphosphatidylcholine and poloxamer 188 as surfactant. The obtained nanoparticle particle size is small at $100 \mathrm{~nm}$ with a good size distribution. Because the melting point of glyceryl behenate is about $70^{\circ} \mathrm{C}$, in the preparation process, the temperature should be higher than $70^{\circ} \mathrm{C}$ to maintain its molten state and ultimately the optimum emulsifying temperature was determined to be $80^{\circ} \mathrm{C}$. Stirring speed was another factor affecting the nanoparticle size. If the speed was too low, the particle size tended to increase and its stability also became bad; if the speed was too high, a large amount of foam would be produced in the preparation, which directly affected the emulsifying effect of surfactant. Finally, the optimum stirring speed was determined to be $1000 \mathrm{rpm}$.

Zeta potential was related to the stability of nanoparticles. Determination of zeta potential contributed to judging the stability of nanoparticle dispersions. ${ }^{13}$ According to diffuse 
Table 7 The results of method recovery in plasma $(n=3)$

\begin{tabular}{lllll}
\hline $\begin{array}{l}\text { Added } \\
(\mu \mathrm{g} / \mathrm{mL})\end{array}$ & $\begin{array}{l}\text { Found } \\
(\mu \mathrm{g} / \mathrm{mL})\end{array}$ & Recovery (\%) & Mean (\%) & RSD (\%) \\
\hline 20.0 & 20.55 & 102.75 & & \\
20.0 & 19.85 & 99.25 & 100.78 & 1.78 \\
20.0 & 20.07 & 100.35 & & \\
2.0 & 1.95 & 97.50 & & \\
2.0 & 2.07 & 103.50 & 100.33 & 3.00 \\
2.0 & 2.00 & 100.00 & & \\
0.2 & 0.21 & 105.00 & & \\
0.2 & 0.21 & 105.00 & 106.67 & 2.71 \\
0.2 & 0.22 & 110.00 & & \\
\hline
\end{tabular}

Abbreviation: RSD, relative standard deviation.

double layer theory, the particle surface charge could directly affect repulsive potential energy between particles and solvation, which affects the heterogeneous system stability. The mean zeta potential of prepared S-SLNs was $-16.37 \mathrm{mV}$, therefore the nanoparticle suspension system was not very stable. The main reason for instability was that the membrane materials were oxidized easily. However, liposomes with SLNs could improve the antioxidation effect of SLN preparation. ${ }^{14}$ In addition, freeze-drying can be used to improve the liposome stability ${ }^{15}$ A cryoprotectant could maintain the stability of liposome membranes and significantly reduce the speed of oxidation and hydrolysis of drug and liposome. Besides, cryoprotectant could form an eutectic or glassy substance with water, which inhibits the growth of ice crystals, and reduces extrusion and mechanical damage to the nanoparticles. ${ }^{16}$ Consequently, the S-SLN lyophilized powders were prepared by freeze-drying and stored at $4^{\circ} \mathrm{C}$ in this experiment. We found that the particle size had no significant change after 3 months, which means that our method is feasible for producing S-SLNs.

To simulate the release profile of drug in vivo, PBS $(\mathrm{pH}=7.4)$ was chosen as the release medium. Because of the

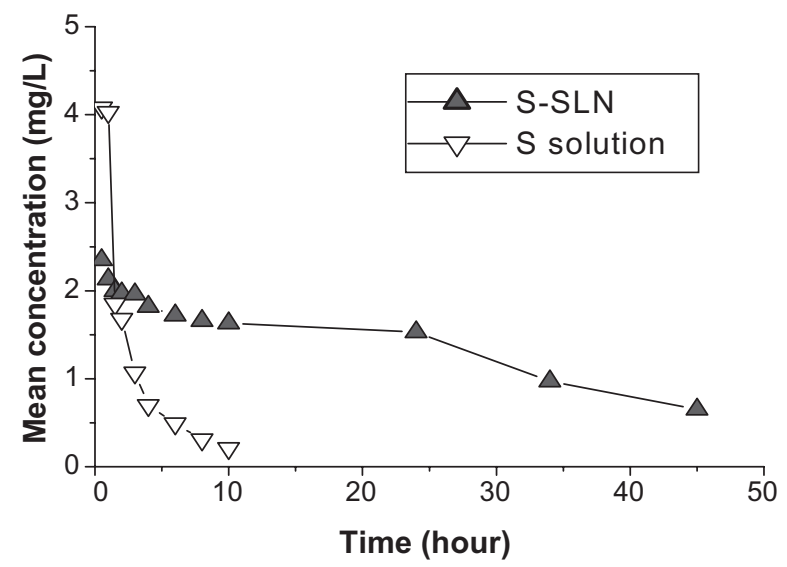

Figure 9 The mean concentration-time curve of sorafenib in plasma after iv administration sorafenib and S-SLN in rabbits $(n=4)$. Abbreviation: S-SLN, sorafenib solid lipid nanoparticle.
Table 8 Plasma pharmacokinetic parameters after intravenous administration of sorafenib solution in rabbits $(n=4)$

\begin{tabular}{lll}
\hline Parameters & Value & SE \\
\hline $\mathrm{A}(\mathrm{mg} / \mathrm{L})$ & 5.13 & 1.39 \\
$\alpha\left(\mathrm{h}^{-1}\right)$ & 1.09 & 0.38 \\
$B(\mathrm{mg} / \mathrm{L})$ & 1.53 & 0.55 \\
$\beta\left(\mathrm{h}^{-1}\right)$ & 0.20 & 0.04 \\
$\mathrm{~V}_{\mathrm{c}}(\mathrm{L} / \mathrm{kg})$ & 3.00 & \\
$\mathrm{t}_{1 / 2 \alpha}(\mathrm{h})$ & 0.63 & \\
$\mathrm{t}_{1 / 2 \beta}(\mathrm{h})$ & 3.44 & \\
$\mathrm{~K}_{21}\left(\mathrm{~h}^{-1}\right)$ & 0.41 & \\
$\mathrm{~K}_{10}\left(\mathrm{~h}^{-1}\right)$ & 0.54 & \\
$\mathrm{~K}_{12}\left(\mathrm{~h}^{-1}\right)$ & 0.35 & \\
$\mathrm{AUC}[(\mathrm{mg} / \mathrm{L}) \cdot \mathrm{h}]$ & 12.29 & \\
$\mathrm{CLs}[(\mathrm{mg} / \mathrm{kg}) / \mathrm{h} /(\mathrm{mg} / \mathrm{L})]$ & 1.63 & \\
\hline
\end{tabular}

Abbreviations: $A \cup C$, area under curve; $C L s$, clearance rates.

strong hydrophobicity of sorafenib, $1 \%(\mathrm{w} / \mathrm{v})$ of Tween- 80 as surfactant was added to the release medium to promote sorafenib solubility in the surrounding release medium. As observed from the release curve of S-SLN in vitro, the release process can be divided into two stages: burst release and sustained release. The large ratio of surface area and volume of SLN and surfactant promoted rapid drug release, with a later slow continuous drug release with the gradual dissolution of the lipid skeleton of the SLN. Part of the drug was adsorbed on the shallow surface or existed in free drug form, with most of the drug wrapped in the lipid skeleton.

3P97 software was used to fit the compartment model of the drug in plasma of average concentration-time curve. According to AIC and $r^{2}$, the smaller the AIC value, the larger the $r^{2}$ value, which shows a good fit for the selected model and drug metabolism. From the pharmacokinetic parameters, the AUC of S-SLN and sorafenib solution was $87.06(\mathrm{mg} / \mathrm{L} \cdot$ hour $)$ and 12.29 ( $\mathrm{mg} / \mathrm{L} \cdot$ hour), respectively, which shows great improvement in the bioavailability of SLN preparation compared with the control group. The half-life of the SLN group was 28.50 hours, but was 3.44 hours in the control group, which may be because the drug was wrapped into the solid lipid matrix to avoid the metabolism action of CYP enzymes, or that sorafenib

Table 9 The plasma pharmacokinetic parameters after intravenous administration of S-SLN in rabbits $(n=4)$

\begin{tabular}{lll}
\hline Parameters & Value & SE \\
\hline $\mathrm{C}_{0}(\mathrm{mg} / \mathrm{L})$ & 2.12 & 0.07 \\
$\mathrm{~K}_{\mathrm{e}}\left(\mathrm{h}^{-1}\right)$ & 0.02 & 0.00 \\
$\mathrm{~V}_{\mathrm{C}}(\mathrm{L} / \mathrm{kg})$ & 9.45 & \\
$\mathrm{t}_{1 / 2(\mathrm{Ke})}(\mathrm{h})$ & 28.50 & \\
$\mathrm{AUC}[(\mathrm{mg} / \mathrm{L}) \cdot \mathrm{h}]$ & 87.06 & \\
$\mathrm{CLs}[(\mathrm{mg} / \mathrm{kg}) / \mathrm{h} /(\mathrm{mg} / \mathrm{L})]$ & 0.23 & \\
\hline
\end{tabular}

Abbreviations: AUC, area under curve; CLs, clearance rates. 
was released slowly from the SLN and stayed in the systemic circulation for a long time. ${ }^{17}$ Moreover, the prepared S-SLN was administered by intravenous injection to avoid adverse reactions in the gastrointestinal tract from oral administration. ${ }^{18}$

Blanchet et $\mathrm{al}^{9}$ and Afify et $\mathrm{al}^{10}$ reported the determination of sorafenib in plasma by HPLC with the wavelengths of $255 \mathrm{~nm}$ and $254 \mathrm{~nm}$. We used these wavelengths to determine sorafenib in plasma, but the results were not satisfactory. Further exploration was performed to obtain a better detection wavelength. When the wavelength was set at $265 \mathrm{~nm}$, the sensitivity was improved and the minimum detectable concentration was $100 \mathrm{ng} / \mathrm{mL}$. In addition, endogenous substances in plasma do not interfere with the determination of sorafenib, which indicates that this method is suitable for the determination of sorafenib in plasma.

\section{Conclusion}

The emulsion evaporation-solidification method at low temperatures was appropriate for S-SLN preparation. The nanoparticles were produced with stable physical properties and demonstrated significant sustained release. The pharmacokinetic behavior of sorafenib is significantly improved by lyophilized injection of SLN with obvious sustained drug release and high bioavailability. The HPLC method used for the determination of sorafenib in plasma was further optimized. In general, the results obtained for in vitro and in vivo release tests are promising and the S-SLN was prepared successfully. Future experiments will be done to investigate the tissue distribution of S-SLN in vivo.

\section{Acknowledgments}

The authors are grateful to Wuhan University for equipment support. In addition, the authors are much grateful to Dr Yin for editing the manuscript.

\section{Disclosure}

The authors report no conflicts of interest in this work.

\section{References}

1. Wilhelm SM, Carter C, Tang L, et al. BAY 43-9006 exhibits broad spectrum oral anti-tumor activity and targets the RAF/MEK/ERK pathway and receptor tyrosine kinases involved in tumor progression and angiogenesis. Can Res. 2004;64(19):7099-7109.

International Journal of Nanomedicine

\section{Publish your work in this journal}

The International Journal of Nanomedicine is an international, peerreviewed journal focusing on the application of nanotechnology in diagnostics, therapeutics, and drug delivery systems throughout the biomedical field. This journal is indexed on PubMed Central, MedLine, CAS, SciSearch $\AA$, Current Contents $₫ /$ Clinical Medicine,
2. Wilhelm S, Carter C, Lynch M, et al. Discovery and development of sorafenib: a multikinase inhibitor for treating cancer. Nat Rev Drug Discov. 2006;5(10):835-844.

3. Mori S, Cortes J, Kantarjian H, Zhang W, Andreef M, Ravandi F. Potential role of sorafenib in the treatment of acute myeloid leukemia. Leuk Lymphoma. 2008;49(12):2246-2255.

4. Ravandi F, Cortes JE, Jone D, et al. Phase I/II study of combination therapy with sorafenib, idarubicin, and cytarabine in younger patients with acute myeloid leukemia. J Clin Oncol. 2010;28(11):1856-1862.

5. Lathia C, Lettieri J, Cihon F, Gallentine M, Radtke M, Sundaresan P. Lack of effect of ketoconazole-mediated CYP3A inhibition on sorafenib clinical pharmacokinetics. Cancer Chemother Pharmacol. 2006;57(5): 685-692.

6. Li YC, Dong L, Jia A, Chang XM, Xue H. Preparation of solid lipid nanoparticles loaded with traditional Chinese medicine by high-pressure homogenization. South Med Univ. 2006;26(5):541-544.

7. Chen H, Chang X, Du D, et al. Podophyllotoxin-loaded solid lipid nanoparticles for epidermal targeting. J Control Release. 2006;110(2): 296-306.

8. Liu J, Hu W, Chen H, Ni Q, Xu H, Yang X. Isotretinoin-loaded solid lipid nanoparticles with skin targeting for topical delivery. Int J Pharm. 2007;328(2):191-195.

9. Blanchet B, Billemont B, Cramard J, et al. Validation of an HPLC-UV method for sorafenib determination in human plasma and application to cancer patients in routine clinical practice. J Pharm Biomed Anal. 2009;49(4):1109-1114.

10. Afify S, Rapp UR, Hogger P. Validation of a liquid chromatography assay for quantification of the Raf kinase inhibitor BAY 43-9006 in small volumes of mouse serum. J Chromatogr B Analyt Technol Biomed Life Sci. 2004;809(1):99-103.

11. Service RF. Nanomaterials show signs of toxicity. Science. 2003; 300(5617):243.

12. Handy RD, Henry TB, Scown TM, Johnston BD, Tyler CR. Manufactured nanoparticles: their uptake and effects on fish-a mechanistic analysis. Ecotoxicology. 2008;17(5):396-409.

13. Chen JF, Zhang DR, Zhang XS, Xing J. Preparation and material phase analysis of solid lipid nanoparticles loading matrine. J Chin Pharm. 2005;36(4):214-217.

14. Liu J, Gong T, Wang CG, Zhong Z, Zhang Z. Solid lipid nanoparticles loaded with insulin by sodium cholate-phosphatidylcholine-based mixed micelles: Preparation and characterization. Int J Pharm. 2007; 340(1-2):153-162.

15. Zhu SS. New Formulation of Drug. Beijing, China: Chemical Industry Press; 2003:435-436.

16. Kurihara A, Shibayama Y, Mizota A, et al. Enhanced tumor delivery and antitumor activity of palmitoyl rhizoxin using stable lipid emulsions in mice. Pharm Res. 1996;13(2):305-310.

17. Hancock BC, Zografi G. Characteristics and significance of the amorphous state in pharmaceutical systems. J Pharm Sci. 1997;86(1): $1-12$.

18. Qin SK, Gong XL. Progress on sorafenib therapy for primary hepatic carcinoma. Chin Clin Oncol. 2008;13(12):1057-1068.
Journal Citation Reports/Science Edition, EMBase, Scopus and the Elsevier Bibliographic databases. The manuscript management system is completely online and includes a very quick and fair peer-review system, which is all easy to use. Visit http://www.dovepress.com/ testimonials.php to read real quotes from published authors. 